\title{
ETNOGRAFANDO A PRAÇA: OS PRIMEIROS OBSTÁCULOS DE UMA ETNOGRAFIA
}

\author{
Gabriela da Costa Araújo ${ }^{1}$ \\ Antônio Mauricio Dias da Costa $^{2}$
}

\section{Introdução}

A pesquisa começou a se desenvolver a partir de uma motivação particular, é quando começo a me questionar sobre algumas formas de usos e apropriações do espaço da Praça do Carmo em Belém do Pará, após alguns contatos preliminares. Nesse momento, vejo que me aproprio do meu papel de pesquisadora (Goffman, 1993), pois, após estes contatos preliminares, me inquieto em saber como se dá o processo de utilização da Praça do Carmo, pelos atores sociais que se fazem ali presentes, como os moradores, os produtores culturais e os frequentadores, que se utilizam do espaço de forma diversa. Pois, ao mesmo tempo em que a Praça é um espaço urbano, de ressignificação constante, é também um patrimônio cultural, que visa a sua preservação, portanto, o que me leva há enxergar limites no seu uso.

A Praça do Carmo, que se localiza no Centro Histórico da cidade de Belém, que é constituído como um bem tombado por fazer parte do Conjunto Arquitetônico, Urbanístico e Paisagístico do bairro da Cidade Velha, pelo IPHAN $^{3}$ (Instituto do Patrimônio Histórico Artístico e Nacional), assim como pela Fundação Cultural do Município de Belém - FUMBEL ${ }^{4}$. Com isso, me questiono como aqueles atores sociais (moradores do bairro, frequentadores e produtores culturais), que se fazem presentes naquele espaço, se relacionam e se apropriam do mesmo? Quais as regras que regem o uso do espaço? Se há ou não conflitos nessa interação? Como cada grupo de atores sociais reconhece este espaço? Qual a compreensão de patrimônio que estes atores possuem?

\footnotetext{
${ }^{1}$ Universidade Federal do Pará, Brasil.

${ }^{2}$ Universidade Federal do Pará, Brasil.

${ }^{3}$ Ver: www.iphan.gov.br

http://portal.iphan.gov.br/montarDetalheConteudo.do;jsessionid=1DAFC9D328137AEE3E707EB591F92 CBC?retorno=detalheNoticia\&sigla $=$ Noticia\&id $=15967$

(Acesso em: 06/09/2014).

${ }^{4}$ Ver: www.belem.pa.gov.br

http://www.belem.pa.gov.br/segep/download/coletanea/PDF/n_urban_p/patr_hist.pdf

(Acesso em 06/09/2014).
} 
Assim, após essa breve explicação do que me levou a realizar a pesquisa, acredito já é possível explicar o foco deste artigo. Neste trabalho procuro desenvolver uma análise acerca da minha relação com o campo da minha pesquisa, a Praça do Carmo, pesquisa esta que já resumi acima. Neste artigo exploro os meus primeiros impasses com a minha inserção no campo, assim como as minhas inquietações e dúvidas sobre como operar no campo. Procuro analisar quais os parâmetros metodológicos a ser utilizado em um campo diverso, que se caracteriza por ser um espaço urbano e patrimonial.

No entanto, um dos primeiros impasses que me vejo a enfrentar é que a minha inserção no campo não seria o meu primeiro contato com o local, pois já havia frequentado o espaço outras vezes, o que fazia daquele espaço familiar. E esta é uma característica, que poderia acarretar em alguns problemas para o desenvolvimento da pesquisa. Foi neste momento, que comecei a me questionar de como realizar esta pesquisa no campo, sem deixar que a minha familiaridade com o espaço interfira nos resultados? Com isso, um dos primeiros caminhos que pretendo seguir no meu campo, foi conceber o outro/grupo estranhamente, seguindo a proposta de Gilberto Velho (2013: 26-27).

[...] Quero deixar claro que quando comecei a preocupar-me com o assunto, tinha a minha 'imagem' de Copacabana e que era, evidentemente, uma situação bastante diferente de um antropólogo europeu que chega a uma tribo do Leste africano, por exemplo. Faço questão de deixar claro, pois este é, talvez, o problema fundamental que o antropólogo enfrenta ao estudar sua própria sociedade. [...] mas sem duvida introduz uma dimensão nova para o trabalho antropológico [...] necessidade de um esforço de autodefinição do investigador não só no começo, mas no decorrer de todo o seu trabalho [...].

É a partir das inquietações com a inserção e a pesquisa em campo que procuro desenvolver este artigo. Busco discutir a metodologia de pesquisa que utilizei para os primeiros passos da etnografia. Porém antes de fazer uma análise dos caminhos da etnografia a ser desenvolvida, acredito ser necessário identificar o contexto histórico e social em que este espaço é praticado e representado. Assim, o artigo seguirá três caminhos: a apresentação do espaço, Cidade, bairro e Praça; discussão sobre a orientação metodológica adotada e a apresentação das minhas primeiras experiências no campo. 


\section{De Belém à Praça do Carmo: aqui fica o meu campo}

A formação da Praça do Carmo confunde-se com a fundação da cidade de Belém, e o surgimento do bairro. Belém faz parte do Estado do Pará, como a sua capital, se localizando na região Amazônica, ao norte do Brasil. Sua fundação ocorreu em 12 de janeiro de 1616, pelo então capitão, na época, Francisco Caldeira Castelo Branco, que vinha em missão de proteger a região Amazônica, Penteado (1968: 95):

O fundador de Belém partira do Maranhão, com uma frota composta de três embarcações tripuladas por 150 homens; acompanhando a recortada costa do Pará, adentrou s baia do Marajó e, passando por entre o grupo das que dão origem à estreita baía do Guajará, junto à barra do rio Guamá, encontrou um local excelente para edificação de um forte, pois 'agradou-se Castelo Branco de um ponta de terra, inacessível pela parte do mar (sic) e defendida pela parte da terra por extensão igarapé, que nascendo do alagadiço do Piri ia desembocar onde hoje é a doca do Ver-O-Pêso. Neste ponto construí êle um Forte de madeira coberto de palha, [...], a que denominou Presépio, não só porque aquela ponta alta dava aquela aparência a quem viesse da baía de Guajará, como porque partira no dia de Natal, do Maranhão'.

Assim, se concebeu a cidade, e ao redor do Forte um povoado se formou, no qual, incialmente foi denominado de Feliz Luzitânia e logo depois de Santa Maria do Grão Pará, Santa Maria de Belém do Grão Pará e por fim, Belém do Pará. Com uma formação de um povoado ao redor do Forte, foram se constituindo caminhos que eram abertos em mata virgem, que logo depois se tornaram as primeiras ruas da cidade, dando assim ao processo de consolidação para um dos primeiros bairros da cidade, o bairro da Cidade Velha.

A Cidade Velha é um dos bairros mais antigos da cidade de Belém, assim como o bairro da Campina, e mais precisamente é o local de origem da cidade. Este bairro abarca dentro da sua estrutura grandes representações de épocas, como a Belém Colonial (Entre o século XVII a meados do século XIX) e a Belém da Belle Époque, que foi um momento no período da Borracha (Século XX) ${ }^{5}$, em que a cidade passou por um processo denominado por muitos como de embelezamento e modernização (Leão, 2011; Miranda, 2006). Em que, este processo deixou suas marcas no bairro, pois quando você caminha pelas ruas do mesmo, é possível observar em seus prédios, casas e

\footnotetext{
${ }^{5} \mathrm{O}$ período conhecido como o ciclo da borracha, foi um momento importante para a história econômica e social de Belém, relacionado com a extração do látex e comercialização da borracha. Proporcionou expansão da colonização, atração de riqueza, transformações culturais e sociais, e grande impulso ao crescimento da cidade (Miranda, 2006).
} 
Igrejas, que hoje representam o patrimônio cultural e urbano da cidade, segundo Fortuna (2006: 03):

[...] São patrimônios históricos edificados, mas também patrimônios sócio culturais, artísticos, linguísticos e humanos que encontram expressões diversas nas cidades de hoje, embora não exclusivamente. Estes patrimônios, tanto dos tangíveis como os intangíveis, enunciam modos de viver passados e actuais que, no seu conjunto, constituem a memória social e, em muitos casos e por isso mesmo, revelam e significam o próprio espírito dos lugares.

A importância da arquitetura e da história presente nos prédios, nas igrejas, casas e Praças do bairro, foi ganhando visibilidade pelos órgãos responsáveis pela preservação do patrimônio, e algumas medidas começaram a ser tomadas para a preservação do bairro, como pode ser observado em Miranda (2006: 55):

No Pará, as primeiras medidas oficiais com relação à preservação do patrimônio ocorreram na década de 60, quando foi publicada a Lei $n^{\circ} 6.307$ de 03 de abril de 1967, que 'Limita a área da Cidade Velha para sua preservação histórica e dá outras providências'. [...]. No Art. $6^{\circ}$, a Lei determina que 'todas as obras de construção nova ou de reforma, obedecerão ao estilo tradicional do Bairro em suas características peculiares, cor, proporções, forma, sempre em equilíbrio com o conjunto arquitetônico existente. '. E acrescenta no artigo $8^{\circ}$ que as intervenções deverão estar vinculadas ao espírito colonial predominante no bairro

Com isso, a partir dessas primeiras intervenções, que cito acima, em relação à preservação do patrimônio, abriu-se caminhos para muitas outras intervenções, assim, alguns prédios históricos do bairro, passaram por esse processo, renovando as suas estruturas que já estavam degradas, entre eles destaco o restauro da Igreja de São João Batista, que foi entregue este ano (2013) ${ }^{6}$.

O bairro abriga as principais igrejas da cidade, como a Catedral Metropolitana da Sé, de Nossa Senhora do Carmo (que deu origem a Praça do Carmo), de São João Batista, de Santo Alexandre e tantas outras, assim como, foi neste bairro, que as primeiras ruas de Belém surgiram, como a rua do Espírito Santo (atualmente Dr. Assis) e a rua do Norte (atual Siqueira Mendes), entre outras, Penteado (1968: 100):

\footnotetext{
${ }^{6}$ Ver: No site do Iphan- Instituto de Patrimônio Histórico Artístico Nacional http://portal.iphan.gov.br/portal/montarDetalheConteudo.do?id=18010\&sigla=Noticia\&retorno=detalheN oticia (Acesso em 30/03/2015).
} 
[...] veio dar origem à primeira rua de Belém, acompanhava a escarpada do terraço do sítio primitivo da cidade pelo lado do Guamá; era muito plano e se desenvolvia numa altitude situada em torno de cota dos 9m; transformou-se na então chamada rua do Norte, atual rua Siqueira Mendes cuja extensão, da praça Frei Caetano Brandão até a frente da Igreja do Carmo [...].

Além da sua importância histórica, o bairro é um local de grande expressão cultural que varia entre as atividades religiosas, como o Círio ${ }^{7}$, as carnavalescas, como o carnaval $^{8}$ de rua, que ocorrem na Praça do Carmo, assim como, outras atividades culturais como o Auto do Círio ${ }^{9}$ (Teatro de rua) e o Arraial do Pavulagem ${ }^{10}$. Em que, se observa a partir da relação do público/cidadãos com os eventos, o quanto estes se identificam e se sentem representados por essas expressões culturais. Pois a cultura da cidade, se expressa nos seus cidadãos, já que a maneira de ser d um cidadão também é moldada pela sua vivência na cidade (Jeudy e Jacques, 2006).

E o que deve ser destacado é que o bairro possui uma história, uma memória, o que faz dele um local de reconhecimento histórico e sensível para a sua cidade. E como pode ser observado na obra de Maurice Halbwachs (2006), ao trabalhar a memória coletiva, destaca que os marcos sociais da memória coletiva, são destacado de duas formas, pelo marco temporal e espacial. No marco temporal, se têm as datas comemorativas, períodos de celebração, etc. Já no marco espacial, a memória é vivida a partir dos lugares (casas, Praças, bairros, etc.). Nesses dois marcos, a memória do bairro é sempre reconstruída, mas o marco espacial está constantemente reconstituindo lembranças, Halbwachs (2006: 170):

\footnotetext{
${ }^{7} \mathrm{O}$ Círio de Nazaré que também ocorre neste bairro, com o inicio da sua procissão, é uma das maiores amostras da devoção religiosa, católica, que se encontra no Estado do Pará, em homenagem a N. Sra. de Nazaré. Foi no ano de 1792 que o vaticano autorizou que se fizesse uma procissão em homenagem a Virgem de Nazaré mas foi somente em 1793 que ela foi realizada. E hoje é uma das festas mais tradicionais do Brasil, “[...] Trata-se de uma festa devocional, [...].”. (Alves 1980: 17).

${ }^{8}$ “O movimento carnavalesco no bairro vem de muito longe. Por volta da década de 40 , existiam no bairro núcleos de concentração de blocos carnavalescos, como na casa da Dona Branca, na Gurupá entre Cametá e Rodrigues dos Santos e na casa dos 'Mangabeira', na Cametá. O filho da D. Branca - conhecida doceira - é cantor de boleros e participava ativamente desses blocos [...].”. (Miranda, 2006: 152)

${ }^{9} \mathrm{O}$ Auto do Círio é um teatro de rua, que ocorre toda sexta-feira que antecede, o Círio. É produzido pela Universidade Federal do Pará - Ufpa, juntamente com Instituto de Ciência da Arte - ICA, em que possui como os seus colaboradores os professores e alunos, como os seus organizadores relatam é uma homenagem dos artistas a Nossa Senhora de Nazaré, (Chagas, 2008 e Araújo, 2011).

${ }^{10} \mathrm{O}$ Arrastão do Círio é uma homenagem dos organizadores e brincantes a Nossa Senhora de Nazaré, é promovido pelo Instituto Arraial do Pavulagem, e ocorre todo sábado que antecede o Círio de Nazaré. Assim, que a imagem da Santa chega, finalizando o Círio Fluvial, é recebida pelo o grupo de batuqueiros e brincantes do Arraial do Pavulagem. E quando a imagem segue com a moto-romaria, o Arrastão do Círio segue em direção da Praça do Carmo, (Lima; Gomberg, 2012).
} 
[...] o espaço é uma realidade que dura: nossas impressões se sucedem umas às outras, nada permanece em nosso espirito e não compreenderíamos que seja possível retomar o passado se ele não estivesse conservado no ambiente material que nos circunda. É ao espaço, ao nosso espaço- o espaço que ocupamos, por onde passamos muitas vezes, a que sempre temos acesso e que, de qualquer maneira, nossa imaginação ou nosso pensamento a cada instante é capaz de reconstruir - que devemos voltar a nossa atenção, é nele que nosso pensamento tem de se fixar para que essa ou aquela categoria de lembrança reapareça.

A Praça do Carmo que primeiramente ficou conhecida como Largo do Carmo, encontra-se no bairro da Cidade Velha. E hoje ao sentar-se brevemente nos bancos da Praça, você observa a presença de algumas moradias, comércios, bares, casas de shows, escola e é claro, a Igreja do Carmo, que foi de onde se resultou o surgimento da Praça do Carmo, pois servia como adro para Igreja no período colonial e com tempo foi se constituindo como Praça, Leão (2011: 4):

As primeiras edificações e arruamentos do bairro da Cidade Velha foram surgindo em relação ao forte e ao rio. A Rua do Norte (atual Siqueira Mendes) foi a primeira, paralela ao rio, iniciava-se na praça d'armas e seguia até a residência do CapitãoMor Bento Maciel Parente que em 1626, com a chegada da ordem dos carmelitas calçados, doou o referido terreno para a construção do convento e o primeiro edifício da igreja do Carmo. Parte do terreno que fazia parte do alagadiço da Juçara tornou-se o adro da igreja chamado Largo do Carmo [...].

Assim, em 1626, foi construída uma Igreja de Taipa ${ }^{11}$, destinada ao culto de Nossa Senhora do Monte do Carmo. Esta Igreja passou por diversas reformas, assim como a Cidade de Belém do Pará, entre elas, podemos citar a reforma que foi realizada pelo arquiteto Antônio Landi ${ }^{12}$ em 1766. Neste período a cidade passava por um processo de urbanização, que tinha como objetivo restaurar a parte pobre e decadente da cidade, assim como, firmar o poder da coroa Portuguesa na "Porta da Amazônia" (Miranda, 2006). Atualmente as obras de Landi representam os principais edifícios tombados no Centro Histórico da Cidade de Belém, como a Catedral Metropolitana de Belém, O Palácio dos Governadores, a Casa das Onze Janelas e entre outras.

E é no final do século XIX, pelo favorecimento do período da Borracha, a cidade sofre algumas transformações, que foram promovidas sob o comando do Intendente Antônio Lemos. E é importante destacar que entre estas transformações, se tem a

\footnotetext{
${ }^{11}$ Parede feita de barro ou de cal e areia com estacas e ripas (Ferreira, 2000: 659).

${ }^{12}$ Antônio José Landi ou Giuseppe Antônio Landi foi arquiteto, cartógrafo, astrônomo e desenhista. O mesmo foi responsável por inserir na arquitetura de Belém, novos padrões arquitetônicos, dando um novo nível ao seu contexto cultural e urbano.
} 
delimitação do espaço da Praça, acrescentando-lhe uma nova pavimentação, arborização, uma balaustrada que se apreciava o rio, que hoje é uma ocupação (denominada de Beco do Carmo), e entre outras transformações.

Entre muitas outras transformações que a Praça sofreu com o tempo, há ocorrida nos anos 90, também teve uma importância significativa na alteração da sua configuração espacial. Com esta reforma, foram implantados na configuração da Praça, o Anfiteatro e a exposição das escavações arqueológicas, das ruínas dos alicerces da Igreja Nossa Senhora do Rosário dos Homens Brancos. Esse sítio arqueológico compõe três "janelas" no espaço da Praça, que atualmente encontram-se subutilizadas, pois nelas não encontramos sinalização com informações sobre o espaço e o local se tornou um "deposito de lixo", que acaba prejudicando e comprometendo a estrutura arqueológica, Sanjad; Leão; Gomes, (2009: 6):

[...] Segundo a Diretora de Patrimônio da Secretaria do Estado do Pará de Cultura o maior erro da ultima reforma se deu pelo fato de ela não ser concluída, pois foi interrompida na fase de programação visual, dificultando a leitura dos seus elementos, perdendo o seu sentido. [...].

Hoje a Praça é um espaço composto pelo anfiteatro, por alguns bancos e pelas “janelas” arqueológicas. E a utilização desses espaços se dá de forma variada, pois como Andrade (2008), nos relata a Praça possui uma diversidade de funções, que englobam a utilização de sua estrutura. Assim, acredito que é preciso pensar neste espaço, como um espaço público diversificado no uso da sua configuração espacial.

E é importante se ressaltar que para a consideração da Praça do Carmo, especificamente os seus espaços de sociabilidade, como espaço público, se valeu da análise de Leite (2004), pois para o autor um espaço urbano somente se estabelece como um espaço público quando nele se unificam certas configurações espaciais (característica do espaço urbano) e um conjunto de ações (característica da esfera pública). Pois, segundo Leite (2004), “[...] a partir dessa relação entre espaço e ação, as práticas interativas atribuem sentidos aos lugares, que por sua vez contribuem para a estruturação dessas ações [...].”.

Com isso, sabe-se que nem todo espaço urbano é um espaço público, já que para ser definido como tal, o espaço urbano precisa que as ações lhe proporcionem sentidos. Para Leite (2004), assim como para Hannah Arendt (2007), o espaço público é um 
espaço onde os sujeitos atuam através da ação e do discurso, um espaço de visibilidade. É um espaço que é necessário para promover a força de experiências, para tornar o homem visível ao mundo, extraindo-o da privação.

Assim, vejo que a Praça se caracteriza como um espaço público de circulação e sociabilidade, no qual, ocorre uma "sociação", (Simmel, 2006) entre os indivíduos, na medida que esta "sociação" ocorre em forma de agrupamentos que visam interesses temporários ou duradouros. Mas é importante destacar que a "sociação" é qualquer forma de interação, "sociabilidade" não. Simmel (2006) vê a sociedade como parte da interação entre os indivíduos, em que suporta uma distinção entre "forma e conteúdo". Para o autor, os indivíduos possuem diversos conteúdos (motivações), que o fazem interagir a partir deles, gerando uma unidade. No entanto, esses conteúdos isolados não se tornam sociais. E a partir da interação, a busca dos indivíduos pela satisfação de seus interesses, que estes produzem a "sociação". A "sociação" é forma que os indivíduos se unificam, para satisfazerem os seus interesses.

A Praça do Carmo é um espaço em que ocorre uma "sociação" entre os indivíduos, e, na medida em que esta "sociação" ocorre em forma de agrupamentos que visam interesses temporários ou duradouros, e um processo, como o autor mesmo chama de, “jogo no qual se 'faz de conta' que são todos iguais e, ao mesmo tempo, se faz de conta que cada um é reverenciado em particular; e 'fazer de conta' não é mentira mais do que o jogo ou a arte são mentiras devido ao seu desvio da realidade", (Simmel 2006).

\section{Primeiros passos etnográficos}

Durante um grande período a antropologia ficou conhecida por ir atrás do "desconhecido", procurava conhecer o outro. Estudava o que era denominado de exótico, o distante, o antropólogo sempre ia à busca de conhecer outras sociedades. Entretanto, essas características mudaram com o tempo, o "desconhecido" não estava mais tão distante assim, e o antropólogo começou a se interessar por compreender a sua própria sociedade. O campo de pesquisa começou a englobar, lugares familiares e com pessoas familiares, no entanto, essa nova abordagem antropológica levantou questionamentos, um deles era, como proceder metodologicamente para que a relação do pesquisador como o objeto não interfira na produção da pesquisa? E essa pergunta 
que me faço quando analiso o meu objeto de estudo. Será que estou fazendo uma etnografia confiável? A minha familiaridade com espaço e com os eventos não irão interferir na minha etnografia?

Com isso, me voltei ao método etnográfico, que é uma característica da Antropologia (Rocha; Eckert 2008, Magnani 2002), mas que hoje também é presente em outras áreas. A etnografia é característica da pesquisa Antropológica, como já havia dito antes, que é caracterizada pela coleta de dados concomitante com o trabalho de campo realizado a partir da relação do pesquisador com o objeto. No entanto, quando se pensa na etnografia é preciso desmistificar que a etnografia, é uma busca incessante por uma meticulosidade explicativa (Magnani, 2009), não vemos isso, quando Geertz (2013) defende a descrição densa.

Pois, a etnografia deve ser mais que uma interpretação sobre o "outro", deve ser uma transação com diálogos, em que fique evidente o "outro" no texto etnográfico e o seu relacionamento com o antropólogo, além da própria voz deste último. E no caso da etnografia urbana, sempre pensando na relação do "outro" com a cidade, como bairro, com a rua, com a Praça. Assim, percebe-se que fazer Antropologia na cidade, não é algo fácil como parece, é um intenso trabalho de pesquisa, Velho (2013: 86):

[...] Não creio que o estudo da própria sociedade seja uma heresia dentro da trajetória da reflexão antropológica, mas significa, sem dúvida, uma ampliação e complexificação de nosso campo de estudos. Logo é uma tarefa a ser assumida com todos os riscos e desgastes que envolve.

Assim, comecei a traçar estratégias, para realizar uma etnografia que me ajudasse a desenvolver uma pesquisa adequada, em que conseguisse perceber as minúcias do campo. Assim, logo já imaginava que o meu primeiro contato com a Praça do Carmo, com intuito de realizar o trabalho de campo, não seria uma tarefa fácil. Já que a Praça é um local de relações divergentes, que permanecem e se modificam cotidianamente, e este seria o meu primeiro desafio, conseguir estar atenta a estas relações, sem deixar que elas passem imperceptíveis aos meus sentidos. E é nessas relações, que me inquieto quando me questiono sobre a minha familiaridade com espaço, pois, como iria ter certeza que as situações, que me atentava seriam "relevantes"? Assim, me via em uma "encruzilhada" de estranhar o familiar e familiarizar o estranho, uma tarefa necessária 
quando se opta estudar a sua própria sociedade, já que eu poderia deixar passar por despercebido situações e detalhes importantes que englobam o contexto urbano.

Com isso, achei que primeiramente seria necessário realizar um "olhar de perto e de dentro" (Magnani, 2002), em que poderia perceber a dinâmica do lugar, assim como as minucias das relações existentes entre os atores sociais e a Praça, em que procurei identificar as redes de relações dão sentido ao meu objeto (Agier, 2011). Assim, comecei a me fazer presente na Praça, a participar de alguns eventos que vinham ocorrendo, assim como a utilização de alguns serviços que vinham sendo ofertados no espaço. E é a minha visão analítica e etnográfica de um desses eventos em particular que irei fazer uma breve descrição aqui.

O meu primeiro acesso com o intuito de pesquisar a Praça, ocorreu no inicio do ano de 2014, janeiro e fevereiro, no período do carnaval. Em que, muito dos blocos do carnaval de rua, realizam a sua concentração ou passam pela Praça durante o seu percurso. E ao contrario de muitos trabalhos, a minha pesquisa não tinha um facilitador para a minha inserção aos grupos presentes no espaço, nesse período, o que me trouxe uma grande dificuldade de acesso aos informantes.

Assim, nos meus primeiros dias de observação segui somente com o meu caderno de campo, onde fazia as minhas observações e relatava detalhes da relação dos sujeitos que ali identifiquei, como moradores do bairro, frequentadores e produtores culturais, com a Praça. Entretanto, estabelecer um contato naquele momento era um pouco difícil, já que a maioria estava ali para divertir-se, e eu não possuía nenhum facilitador para proporcionar a minha inserção nos grupos. Assim, neste momento a pesquisa se caracterizou apenas com observações diretas, em que, procurava identificar quais eram as formas de usos e apropriações que ocorriam durante o evento pelos sujeitos que se faziam presentes, o que me proporcionou a identificação do espaço e dos grupos.

Observei, depois de um tempo, que a relação desses grupos com a Praça se dá de forma diversificada, cada um se relaciona de forma particular, assim como, também percebi que alguns grupos que se localizam na Praça de forma específica como se fossem lugares marcados. Por exemplo, os trabalhadores informais se concentravam de um lado da Praça, os brincantes do carnaval se misturavam pelo espaço, os moradores do entorno da Praça se concentravam de um lado oposto dos moradores do Beco do Carmo. 
Com isso, percebi que a complexidade e heterogeneidade das cidades (Velho, 2009), assim como os espaços contextualizados no contexto urbano, colocam o pesquisador a frente de novas dimensões na experiência do comportamento humano. $\mathrm{O}$ que significa que apesar de a Praça do Carmo ser familiar a mim, não significa que eu conheça a percepção de todos os sujeitos que a frequentam e nem as regras que estão por trás das interações entre eles. Foi neste momento que percebi que o familiar não me era tão familiar assim. E o processo de inversão havia se realizado, a minha familiarização com espaço havia se tornado estranha (DaMatta, 1978).

Entretanto, a minha inserção em campo ainda está ocorrendo de forma "branda", como havia dito, pois acredito que preciso primeiro me fazer parte daquele ambiente, para depois tentar algum contato, pois como Victor Turner (2005) argumenta em seu trabalho, o ritual pode ser avaliado de fora da estrutura, o que nesse caso avalio a relação dos sujeitos com a Praça. Assim como, Michel Foucault (1992) e Howard Becker (2009) analisam, o contexto é fundamental para compreendermos as relações. Por isso, optei por avaliar de fora, para compreender o contexto em que o evento ocorria.

Acredito que seja necessário primeiramente manter uma comunicação visual, pois a cidade é o lugar do olhar, onde você vê e é olhado. E percebo que as pessoas que vão a Praça do Carmo estão praticando esta premissa a todo o tempo. Com isso, acredito que preciso me comportar "neoflâneur" (Canevacci, 1997), para poder compreender a relação do sujeito com o objeto, como falam Eckert e Rocha (2008: 2):

[...] As primeiras inserções no universo da pesquisa conhecidas como 'saídas exploratórias', são norteadas pelo olhar atento ao contexto e a tudo que acontece no espaço observado. A curiosidade é logo substituída por indagações sobre como a realidade social e construída. [...].

Devido a esse processo de comunicação que resolvi empregar, primeiramente, então precisei aprimorar os meus sentidos, para poder conceber o que acontecia naquele espaço. Naquele momento estes eram os meus meios para buscar compreender as relações do meu objeto com os sujeitos (Oliveira, 2008).

Por isso, em muitas das visitas a campo, sentava em um dos bancos da Praça, e começava a observar o que acontecia ao meu redor, especificamente a interação dos sujeitos com a Praça. Foram nestes momentos em que percebi como estes sujeitos se 
localizavam no espaço e interagiam entre si, assim como, a presença de novos sujeitos no ambiente. No decorrer destas minhas observações, novos questionamentos sobre os usos e regras que regiam aquele ambiente vinham surgindo, assim como, compreender qual o significado do valor patrimonial que aquele ambiente possui, para aqueles atores sociais.

No entanto, as minhas idas ao campo, não se resumiam até então somente em observar: procurava interagir com o ambiente, caminhando pela Praça e consumindo. Em uma dessas caminhadas, observei que algumas pessoas que estavam na Praça se direcionaram para um lado especifico da Praça, e começaram a se aglomerar em uma fila. Direcionei-me ao espaço para saber o que acontecia. Foi então que lembrei que em uma pequena distancia dali, bem pequena, há uma Casa de Show, o Açaí Biruta, e aquela aglomeração era para entrar no estabelecimento. Foi então que comecei a refletir sobre a complexidade de estudar o objeto da/na cidade, pois quando você realiza uma observação empírica na cidade, é preciso considerar o urbano como um todo (Agier, 2011), mas nunca esquecendo os seus recortes. Observei que naquele momento existiam pessoas que estavam ali, na Praça, somente esperando o horário da Casa de Show abrir. Assim, a Praça é também um local de espera, que era outra característica dos atores sociais que se faziam ali presente, ficar na Praça para "matar o tempo" 13.

No decorrer dessas minhas primeiras idas à Praça, resolvi adotar uma ferramenta a mais, ao meu aparato de trabalho, além do caderno de campo. Resolvi usar a máquina fotográfica. Pois com a fotografia, poderei ter uma auxiliar de uma memória tridimensional, já que tenho o vivido da imagem (Rocha; Eckert, 2003), ao contrario de quem somente vê a imagem. Neste dia que levei a máquina fotográfica, pude captar algumas imagens que mostram como alguns grupos que são geralmente "fixos" se organizam no espaço da Praça.

As minhas idas a campo ainda são poucas para poder firmar um interlocutor, manter um contato, mas acredito que mesmo que esteja no meu último dia em campo, ainda não dá para definir o que a cidade pode me revelar. Pois mesmo, que eu não tenha programado, acredito que é preciso deixar que os acontecimentos do campo me guiem, pois acredito que as relações com os sujeitos podem acontecer de forma natural e simples.

\footnotetext{
${ }^{13}$ Uma expressão que escutei de uma das pessoas, estavam na Praça esperando dar um horário para entrar na casa de show.
} 
Como pode se observar realizar o trabalho de campo, não é uma "receita de bolo", o método a ser utilizado não vem pronto e acabado. O pesquisador que irá descobrindo, de acordo com o tempo e com as temporalidades que seu campo lhe prega. Cada pesquisador vai reinventando a etnografia, de acordo com a sua pesquisa (campoobjeto), (Laura Nader, 2011). Pois o trabalho do antropólogo é continuo.

O espaço da Praça do Carmo é ressignificado pelos sujeitos a todo o momento. E esses usos contribuem para uma diversificação de sentidos dos lugares. Assim, como contra uso, pode ser visto como uma forma de tática de criação de singularidades, em que se reivindica direitos de pertencer à cidade

É preciso pensar que a Praça do Carmo, assim como a Cidade Velha, é um espaço de arte e cultura, fator que é acentuado por sua significação histórico-cultural, por estar no centro histórico da cidade de Belém, “[...] as manifestações de uma sociabilidade pública não eclodem em qualquer rua, mas em certos espaços que têm significações para os atores envolvidos [...].” (Leite, 2008: 49).

A cidade é um lugar de "comportamentos desviantes" (Velho, 1989), do estranho e do familiar. As interações entre os sujeitos refletem e são refletidas pelos espaços. O etnógrafo precisa compreender as entrelinhas dessas interações, para poder compreender a relação do sujeito com a cidade. Com isso, será um trabalho constante, de deslocamentos, observações, interpretações, estranhar o familiar e familiarizar o estranho, é estar preparada para as temporalidades que o campo me oferece.

Já que mesmo, que eu não tenha programado, acredito que é preciso deixar que os acontecimentos do campo me guiem, pois acredito que as relações com os sujeitos podem acontecer de forma natural e simples. E é claro, é um trabalho que não está nem perto do fim, há ainda muitos percursos a se percorrer, há sempre novas estratégias a se empregar e traçar. 


\section{Referências}

AGIER, Michel. Lugares e redes - As mediações da cultura urbana. In: Antropologia da Cidade: lugares, situações, movimentos. p.141-195. São Paulo: Terceiro Nome, 2011.

ALVES, Isidoro. O Carnaval Devoto - um estudo sobre a festa de Nazaré, em Belém. Petrópolis: Vozes, 1980.

ANDRADE, Marcela N. Politicas públicas e espaço urbano: diversos contextos da Praça do Carmo. Monografia (Especialização)- Universidade Federal do Pará, Núcleo de Altos Estudos Amazônicos, Curso Internacional em Cidades NA Amazônia: história, ambiente e culturas, Belém, 2008.

ARAÚJO, Gabriela da Costa. Auto do Círio: Teatro de rua na Cidade Velha. Trabalho de Conclusão de Curso - Instituto de Ciências Humanas, Universidade Federal do Pará, Belém, 2011.

ARENDT, Hannah. A condição Humana. $10^{\circ}$ ed. Rio de Janeiro: Forense Universitária, 2007.

BECKER, H. Falando da Sociedade: ensaios sobre as diferentes maneiras de representar o social. Rio e Janeiro: Jorge Zahar editores, 2009.

CANEVACCI, Massimo. A Cidade Polifônica: ensaio sobre a Antropologia da Comunicação Urbana. São Paulo: Studio Nobel, 1997.

CHAGAS, Eduardo W. Nunes. O Auto do Círio: A carnavalização imagética do Espetáculo. Trabalho de Conclusão de Curso - Instituto de Ciências da Arte, Universidade Federal do Pará, 2008.

DAMATTA, Roberto. O Ofício de Etnólogo, ou como Ter "Anthropological Blues". In: NUNES, Edson de Oliveira (org.). A Aventura Sociológica. Rio de Janeiro: Zahar Editores, 1978. p. 23-35.

FERREIRA, Aurélio Buarque de Holanda. Mini Aurélio Século XXI: o minidicionário da língua portuguesa. $4^{\circ}$ ed. Rio de Janeiro: Nova Fronteira, 2000.

FOUCAULT, Michel. Las meninas, In: As palavras e as coisas. São Paulo: Martins Fontes, 1992. p. 19-31.

FORTUNA, Carlos. Centros Históricos e Patrimônios Culturais Urbanos: Uma avaliação e duas propostas para Coimbra, Oficina do Centro de Estudos Sociais no 254, 2006. p. 1- 13.

GEERTZ, Clifford. A interpretação das culturas. In: Uma Descrição Densa: por uma Teoria Interpretativa da Cultura- $1^{\circ}$ ed., [Reimpr.] - Rio de Janeiro: LTC. 2013 [1926]. p. 3-24.

GOFFMAN, Erving. A Apresentação do Eu na Vida de Todos os Dias. Lisboa: Relógio D’Água, 1993.

HALBWACHS, Maurice. A memória coletiva. São Paulo: Centauro. 2006.

JEUDY, Henri Pierre, JACQUES, Paola Berenstein (Orgs.). Corpos e Cenários Urbanos: Territórios urbanos e políticas culturais. Salvador: Editora EDUFBA, 2006.

LEÃO, Monique B. M. S. O largo do Carmo em Belém/PA: cultura, lazer e conflitos no espaço público, XIV Encontro Nacional da ANPUR. ISSN 1984- 8781, 2011. p. 1-20.

LEITE, Rogerio Proença. Contra-usos da cidade: lugares e espaço público na experiência urbana contemporânea. Campinas: Editora UNICAMP, 2004.

RCCS, no83, 2008. p. 35-54.

Localizando o espaço público: Gentrification e cultura urbana. In:

LIMA, Dula Maria Bento de; GOMBERG, Estélio. Cultura, patrimônio imaterial e sedução no Arraial do Pavulagem, Belém (PA), Brasil. Textos escolhidos de cultura e arte populares, Rio de Janeiro, v.9, n.2, nov. 2012. p. 53-67.

MAGNANI, José Guilherme Cantor. De perto e De dentro: notas para uma etnografia urbana, in Revista Brasileira de Ciências Sociais, vol. 17, 2002. p. 11-29.

No meio da trama. A Antropologia urbana e os desafios da cidade contemporânea. Sociologia, problemas e práticas. CIES/ISCTE-IUL. Lisboa, n. 60, 2009. p. 698.

MIRANDA, Cybelle Salvador. Cidade Velha e Feliz Lusitânia: cenários do patrimônio cultural em Belém. Belém: UFPA, 2006, p. 262. Tese (Doutorado)- Programa de Pós- Graduação em Ciências Sociais - Antropologia, Universidade Federal do Pará, Belém, 2006. 
NADER, Laura. Ethnography as theory. In: Journal of Ethnographic Theory, 1(1), 2011. p. 211-219.

OLIVEIRA, Roberto Cardoso de. O trabalho do antropólogo: olhar, ouvir, escrever. In: $O$ trabalho do Antropólogo, p. 17 - 35. São Paulo: UNESP, 2008.

PENTEADO, Antônio Rocha. Belém - Estudo de geografia urbana. $1^{\circ}$ volume, Coleção Amazônia. Belém: UFPA, 1968.

ROCHA, Ana Luiza C. da.; ECKERT, Cornélia. Etnografia de rua: estudo de antropologia urbana. In: Iluminuras, NUPECS/PPGAS/IFCH/UFRGS, vol. 4, n. 7, 2003. p. 1-22.

Etnografia: Saberes e Práticas. In: PINTO, Célia Regina J.; GUAZZALLI,

Cézar Augusto B.(Orgs.). Ciências Humanas: Pesquisa e Método. Porto Alegre: Editora da Universidade, 2008. p. 1-23.

SANJAD, Thais Alessandra B. C.; LEÃO, Monique B. M. S.; GOMES, Aline N. O Largo do Carmo em Belém-PA: Espaço Público, Patrimônio e Indústria Cultural. In: Encontro da associação Nacional de Pós-Graduação e Pesquisa em Planejamento Urbano e Regional, 8, 2009, Florianópolis. Anais... ANPUR, 2009.

SIMMEL, Georg. A sociabilidade, In: Questões fundamentais da Sociologia. Rio de Janeiro: Zahar, 2006.

TUNER, Victor. Os símbolos no ritual Ndembu. In: Floresta de símbolos: aspectos do ritual Ndembu. Trad. Paulo Gabriel H. R. Pinto. Niterói: EDUFF, 2005 [1967]. p. 49-82.

VELHO, Gilberto. A Utopia Urbana: Um estudo de Antropologia Social. Rio de Janeiro: Jorge Zahar, 1989 [1973].

. Um antropólogo na cidade: Ensaios de Antropologia Urbana. Gilberto

Velho; CASTRO, C.; KUSCHINIR, K.; VIANNA, H. (Orgs.)- Rio de Janeiro: Zahar, 2013.

Antropologia Urbana: Encontro de tradições e novas perspectivas. In:

Sociologia, problemas e práticas, n. 59, 2009. p. 11-18.

Recebido em: 23/03/2015

Aprovado em: 09/06/2015 